\title{
JOURNAL.RU
}

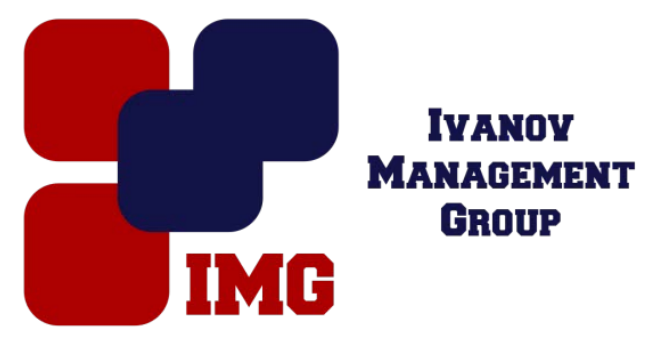

\begin{abstract}
Прудий А.В., Петров С.И., Исаев И.Р., Гудков В.А. Шахтинский институт (филиал) федерального государственного бюджетного образовательного учреждения высшего образования «Южно-Российский государственный политехнический универси-тет (Новочеркасский политехнический институт) имени М.И. Платова Шахты, Россия
\end{abstract}

doi: 10.18411/lj-25-12-2016-1-06

idsp 000001:lj-25-12-2016-1-06

\section{Алгоритм учета скорости и направления движения задающего устройства в селективной системе отопления многоквартирных домов}

\section{Аннотация}

В статье представлен алгоритм учета скорости и направления движения управляющего устройства, применяемый для системы геолокационного управления котлами в котельной и клапанной систевмы для многоквартирных домов.

Ключевые слова: система геолокационного управления, gps, системы глобального позиционирования, учет скорости, автоматическое регулирование, клапанная система управления.

Являясь важной частью народного хозяйства страны, жилищнокоммунальное хозяйство по-прежнему остается одним из самых проблемных секторов экономики нашего государства. Эта отрасль требует выделения на свое содержание и развитие значительного объема финансовых ресурсов. Проблема эффективного содержания и восстановления жилого фонда для России более, чем актуальна. Большинство домов, сегодня находящихся в эксплуатации, являются объектами с низким уровнем энергоэффективности. По данным Госстроя, в России расход тепло-энергии (отопление, горячая вода) составляет 74 кг условного топлива на м2 в год, что в несколько раз выше, чем в Европе. Актуальность этой проблемы нашла отражение в Федеральном законе № 261 Ф3 «Об энергосбережении и о повышении энергетической эффективности, и о 
внесении изменений в отдельные законодательные акты Российской Федерации»(Ссылка на закон в использованных источноках). И хотя в европейских странах энергосберегающие технологии становятся все более популярными, в России им до сих пор не уделяют должного внимания. Однако, система автоматического управления отоплением в доме позволяет значительно снизить расход тепло-энергии.

Создание эффективной, экономически выгодной, экологически чистой и комфортной для потребителя энергосберегающей системы отопления многоквартирного дома позволяет оптимизировать затраты на содержание дома и улучшить качество жизни людей. Так как нерационально расходуют газ на обогрев жилого помещения без присутствия жильцов.Для экономии и энергосбережения предлагаются системы клапанов, которые будут управлять подачей воды в радиатор. Клапаны в свою очередь будут управляться приводами, которые регулируются с помощью термодатчиков в квартире.Так же температура в квартире будет зависеть и от расстояния на котором будет находиться человек, который проживает в квартире (ссылка в используемой литературе).

В настоящее время каждый человек при себе имеет мобильный телефон.Мобильные телефоны снабжены большим количеством датчиков: гироскоп, акселерометр, магнитометр, датчик приближения, датчик освещенности, датчик определения геопозиции и другие. Выше перечисленные факты создают предпосылки для использования смартфонов в качестве основного элемента управления различных технических систем, в частности в системах геолокационного управления системой отопления многоквартирных домов.

На рисунке 1 представлена система дистанционного управления температурой в квартирах в многоквартирных домах, которая в свою очередь является системой геолокационного управления, так как за управляющее воздействие системы принимаются сведения не только от датчиков температуры, установленных в самой квартире, но и от сведений о геопозиции мобильного телефона.

В результате анализа свойств геолокационных систем, в ходе которых было определено, что для получения наиболее точных показаний работы системы и качественного сигнала задающего воздействия необходимо учитывать скорость и направление движения объекта. 
Определение скорости и направления движения задающего устройства можно осуществлять с помощью глобальных навигационных систем (GPS, ГЛОНАСС). Точность позиционирования устройства определяется точностью спутниковых измерений псевдодальности и геометрии их взаимного расположения спутников, с помощью которых выполняются измерения псевдодальности. Фазовые доплеровские измерения сигналов скорости объекта, позволяют определить фактическую скорость со среднеквадратичными отклонениями в диапазоне от 0,01 до 0,05 м/с [2].

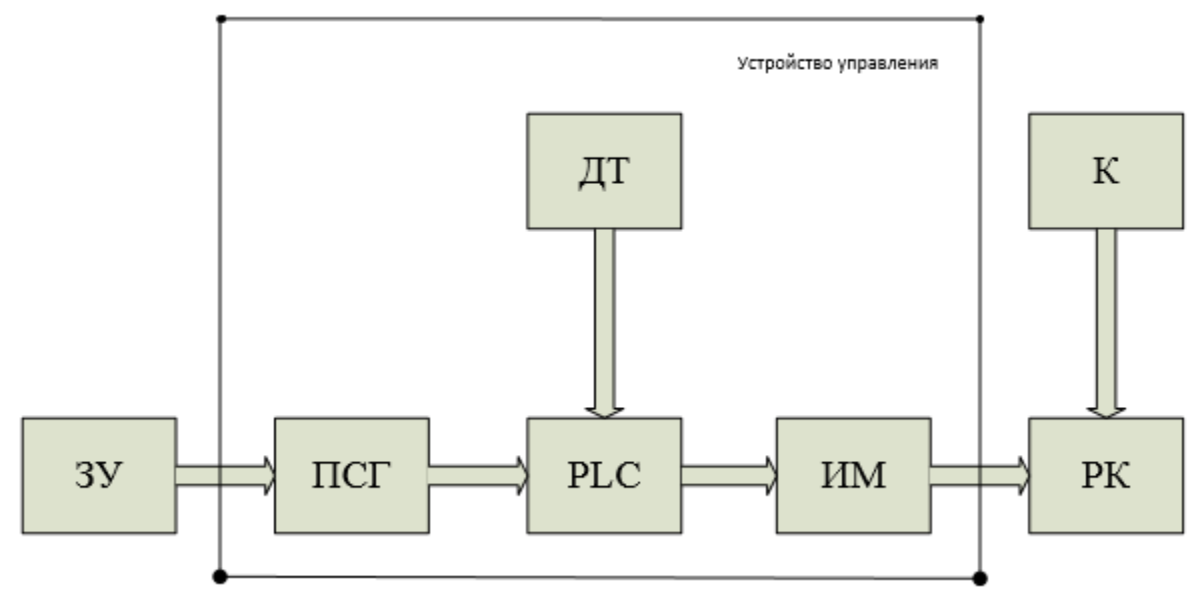

Рис.1 Функииональная схема геолокаиионной системы управления газовыми котлами в котельной

ЗУ - задающее устройство; ПСГ - приемник сигнала о геопозиции; ДТ датчики температуры; PLC - программируемый логический контроллер; ИМ исполнительный механизм; К -котельная; РК- распределительные клапана.

Влияние погрешности спутниковых измерений учитывается с помощью коэффициента, получившего название показателя снижения точности. Точность измерения псевдодальности зависит от ошибок измерений времени полета каждого из спутников. При условии, что электромагнитные радиосигналы от спутников распространяются со скоростью света, небольшие ошибки синхронизации могут вызвать значительные ошибки определения положения. Исходя из этого, все основные источники ошибок можно условно разбить на три основные группы:

ошибки связанные с неточностью знания исходных данных, из которых определяющая роль принадлежит погрешностям знания эфемерид спутников, значения которых должны быть известны на момент измерений;

ошибки, обусловленные влиянием внешней среды среди которых выделяют такие источники, как воздействие атмосферы (ионосферы и 
тропосферы) на результаты спутниковых измерений, а также отраженных от окружающих объектов радиосигналов (многопутность);

инструментальные источники ошибок, к которым, как правило, относятся неточность знания положения фазового центра антенны приемника, неучтенные временные задержки при прохождении информационных сигналов через аппаратуру, а также погрешности, связанные с работой регистрирующих устройств спутниковых приемников.

Наряду с перечисленными выше группами ошибок приходится учитывать и отдельные факторы, обусловливающие появление ошибок, которые не характерны ни для одной из перечисленных выше групп. К таким ошибкам могут быть отнесены погрешности, возникающие вследствие неоптимального взаимного расположения наблюдаемых спутников (геометрический фактор).

Скорость горизонтальных перемещений относительно поверхности земли и курс, рассчитываются из северной и восточной компонент скорости, получаемой глобальной навигационной системой и определяемых по формулам:

$$
\begin{aligned}
& V_{\text {зу }}=\sqrt{V_{c}^{2}+V_{\mathrm{B}}^{2}} \\
& \chi=\tan ^{-1}\left(\frac{V_{\mathrm{c}}}{V_{\mathrm{B}}}\right),
\end{aligned}
$$

где $V_{\text {зу }}$ скорость задающего устройства;

$V_{\mathrm{c}}=V_{\alpha} \cos \psi+w_{\mathrm{c}}-$ северная компонента скорости;

$V_{\mathrm{B}}=V_{\alpha} \sin \psi+w_{\mathrm{B}}-$ восточная компонента скорости;

$\chi-$ курс движения задающего устройства;

$\cos \psi$ - это угол относительно северного меридиана;

$\sin \psi$ - это угол относительно экватора.

Используя основной принцип неопределённости [4], можно оценить измерения скорости относительно земли и курса:

$$
\begin{aligned}
& \sigma_{V_{3 \mathrm{y}}}=\sqrt{\frac{V_{\mathrm{c}}^{2} \sigma_{V_{\mathrm{C}}}^{2}+V_{\mathrm{B}}^{2} \sigma_{V_{\mathrm{B}}}^{2}}{\left(V_{\mathrm{c}}^{2}+V_{\mathrm{B}}^{2}\right)^{2}}}, \\
& \sigma_{\chi}=\sqrt{\frac{V_{\mathrm{c}}^{2} \sigma_{V_{\mathrm{B}}}^{2}+V_{\mathrm{B}}^{2} \sigma_{V_{\mathrm{C}}}^{2}}{\left(V_{\mathrm{c}}^{2}+V_{\mathrm{B}}^{2}\right)^{2}}}
\end{aligned}
$$

Спутнику гораздо проще определить направление движения объекта, если он движется с высокой скоростью, в противном случае возникают погрешности. На этот факт указывает неопределенность масштаба измерений. 
Неопределённость масштаба измерений курса при определении скорости перемещения относительно земли, незначительна для высоких скоростей, а для низких скоростей становится большой[5].

На основании (1) - (4) можно моделировать измерения скорости относительно земли и курса, путем получении данных со спутников GPS[6]:

$$
\begin{aligned}
& y_{G P S, V_{3 y}}=\sqrt{\left(V_{\alpha} \cos \psi+w_{\mathrm{c}}\right)^{2}+\left(V_{\alpha} \sin \psi+w_{\mathrm{c}}\right)^{2}}+\eta_{V} \\
& y_{G P S, \chi}=\operatorname{atan} 2\left(V_{\alpha} \cos \psi+w_{\mathrm{c}}, V_{\alpha} \sin \psi+w_{\mathrm{B}}\right)+\eta_{\chi},
\end{aligned}
$$

где $\eta_{V}, \eta_{\chi}$ случайные числа Гауссова процесса.

При наличии возможности измерения скорости и определения направления движения задающего объекта, необходимо разработать алгоритм работы системы геолокационного управления с учетом этих показателей. Рассмотрим применение представленного алгоритма учета скорости в системе геолокационного управления клапанной системой и котельной для многоквартирных домов.

Для решения поставленной задачи рационально использовать циклический способ построения алгоритма учета скорости и направления движения задающего объекта в геолокационной системе управления клапанной системой и котельной[7].

В результате анализа работы системы было определено, что при различной скорости движения задающего устройства, необходимо менять скорость прогрева помещения, a, следовательно, изменять количество подаваемого топлива в котлы котельной. При приближении задающего устройства к приемнику сигнала о геопозицииклапана будут подавать больше жидкости несущей тепло, производительность котлов в котельной увеличится, а при удалении - клапана сокращают подачи жидкости, а производительность котлов в котельной уменьшится.

На рис. 2 представлен алгоритм работы системы геолокационного управления котлами в котельной и клапанной системы с учетом скорости и направления передвижения задающего устройства. 


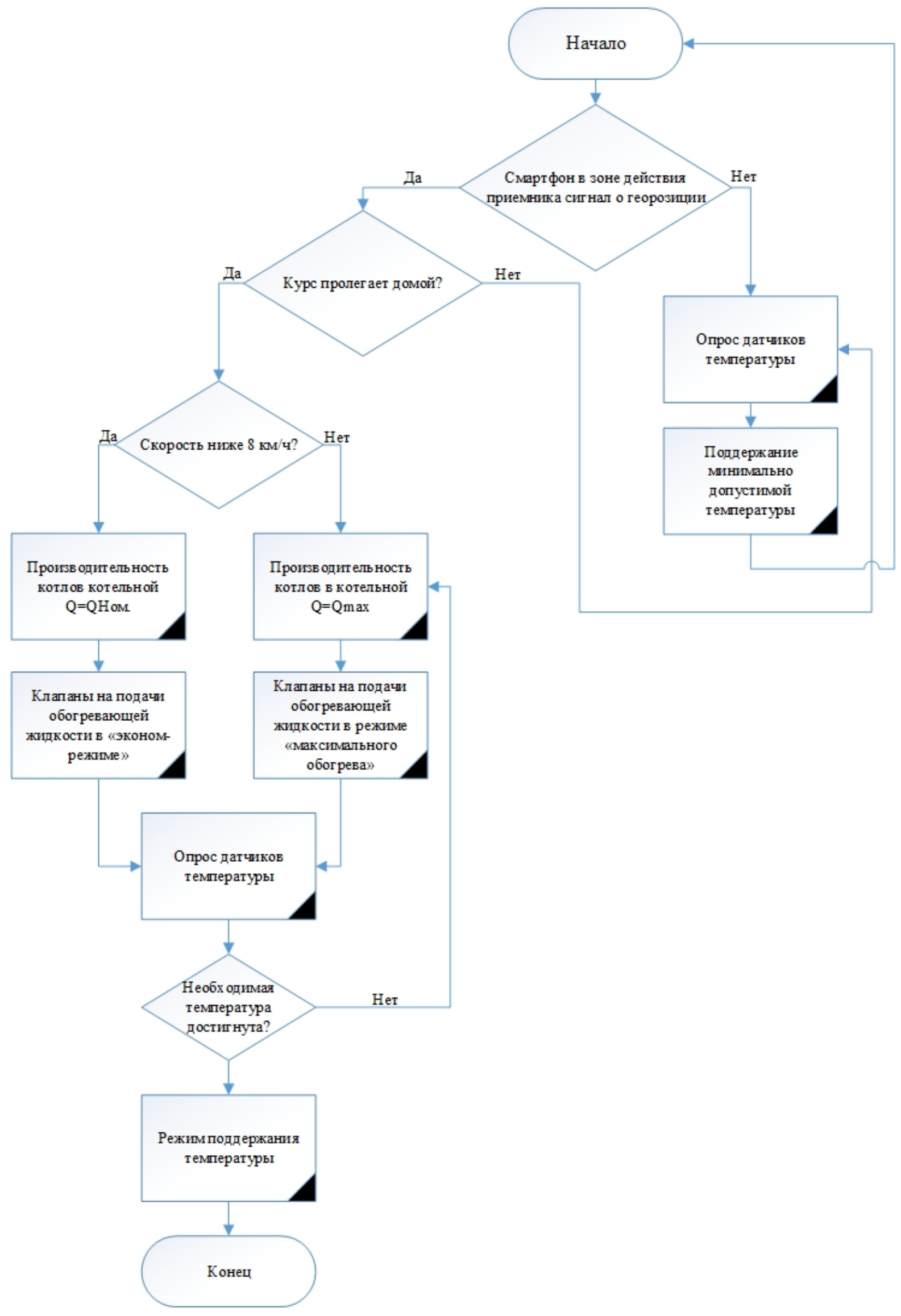

Рис. 2Алгоритм работы системы геолокационного управления котловв котельной с учетом скорости перемещения и направления движения задающего устройства. 
Представленный алгоритм позволяет реализовать следующие возможности:

1. Определение местоположения задающего устройства с высокой точностью;

2. Расчет скорости движения задающего устройства относительно управляющего устройства;

3. Определение направления движения задающего устройства относительно управляющего устройства;

4. Управление исполнительным органом и регулировка параметров системы в зависимости от направления и скорости движения задающего устройства;

5. Распознавание стандартных (заранее запрограммированных) маршрутов ведущих к управляющему устройству. 


\section{Литература}

1. Прудий А.В., Иванов А.В., Орлов Д.А., Золотов И.В. Разработка системы автоматического регулирования температуры в частных домовладениях с применением дистанционного управления. Перспективы развития Восточного Донбасса: материалы VI Международной и 64-й всероссийской науч.-практ. конф., апрель 2015, г. Шахты/ Южно-Российский государственный политехнический университет (НПИ) им. М.И. Платова. - Новочеркасск: ЮРГПУ (НПИ), 2015 - C.128-135.

2. Прудий А.В., Петров С.И, Исаев И.Р. Селективная система отопления многоквартир-ных домов. - Перспективы развития Восточного Донбасса : материалы VII=й Международ-ной 65-й Всероссийской науч.-практ. конф., апрель 2016, г. Шахты / Южно-Российской государственный политехнический университет (НПИ) имени М.И. Платова. - Новочеркасск: ЮРГПУ (НПИ), 2016 - С. 69-72.

3. Дистанционное управление газовым котлом - [Электронный ресурс] URL: http://www.tk-66.ru/distanczionnoe-upravlenie-gazovyim-kotlom

4. Федеральный закон № 261-Ф3 «Об энергосбережении и о повышении энергетической эффективности и о внесении изменений в отдельные законодательные акты Российской Федерации». - [Электронный pecypc] - URL: http://www.energosovet.ru/fzakon.html

5. Parkinson B.W., Spilker J. J., Axelrad P., and Enge P., eds., Global Positioning System: Theory and Applications. Reston, VA: American Institute for Aeronautics and Astronautics, 1996;

6. Figliola R. and Beasley D. Theory and Design for Mechanical Measurements. New York: JohnWiley\& Sons, Inc., 2006;

7. J.-M. Zogg, GPS: Essentials of Satellite Navigation. http://zogg-jm.ch/ Dateien/ GPS_Compendium(GPS-x-02007), 2009.

8. Grewal M. S., Weill L. R., and Andrews A. P., Global Positioning Systems, Inertial-Navigation, and Integration. New Jersey: John Wiley \& Sons, 2nd ed., 2007; 